During the later Cave periods the flake-implements show more skilled workmanship and a greater variety of forms, and this improvement is maintained in the Neolithic age.

The occurrence, however, in the Chelles and St. Acheul periods of most of the types of flake-implements, such as the grattoir, the racloir, and the knife, points to the fact that early palæolithic man was already acquainted with the patterns and methods of making the flake-implements, but for unknown reasons he preferred, or was compelled to use, the core-implement.

Evolution or descent with modification can be traced from some palæolithic to neolithic types, corresponding with changes of conditions and a gradual advance in civilization.

Without the aid of geology no precise chronology among cultural stages could be traced; with its aid, time-relationships can be determined and the serveral types of flint-implements, instead of of being mere objets de vertu, acquire a new value as "zone-fossils".

\title{
II.-Climate and Time.
}

By R. M. Deeley, V.P.G.S.

CIR CHARLES LYELL in his Principles of Geology, published in N 1834, remarks upon the accumulating proofs that the climate of the earth had undergone great changes in the past, and he endeavoured to show that these changes might have been produced by the varying distribution of sea and land. He says, "But if, instead of vague conjectures as to what might bave been the state of the planet at the era of its creation, we fix our thoughts steadily on the connexion at present between climate and the distribution of land and sea; and if we then consider what influence former fluctuations in the physical geography of the earth must have had on superficial temperature, we may perhaps approximate to a true theory."

The attitude adopted by Lyell may be well illustrated by a few quotations from chapter vii of the above-mentioned work :-

"The ocean has a tendency to preserve everywhere a mean temperature, which it communicates to the contiguous land, so that it tempers the climate, moderating alike an excess of heat or cold. The elevated land, on the other hand, rising to the colder regions of the atmosphere, becomes a great reservoir of ice and snow, attracts, condenses, and congeals vapour, and communicates its cold to the adjoining contry." "Among other influential causes, both of remarkable diversity in the mean annual heat, and of unequal division of heat in the different seasons, are the direction of currents and the accumulation of drifting ice in high latitudes." "If we now proceed to consider the circumstances required for a general change of temperature, it will appear, from the facts and principles already laid down, that whenever a greater extent of high land is collected in the polar regions, the cold will augment; and the same result will be produced when there shall be more sea between or near the tropics; while on the contrary, so often as the above conditions are reversed, the heat will be greater. If this be admitted, it will follow as a corollary, that unless the superficial inequalities of the 
earth be fixed and permanent, there must be never-ending fluctuations in the mean temperature of every zone; and the climate of one area can no more be a type of every other, than is one of our four seasons of all the rest."

Lrell goes on to describe the "position of land and sea which might produce the most extreme of cold of which the earth's surface is susceptible", and concludes that if the continents were grouped about the equator the extreme of heat would be experienced, whereas if they were grouped about the poles the extreme of cold would be attained.

There is nothing in Lyell's writings to lead us to suppose that he thought that the continents were ever grouped in this way. He assumes such an arrangement as an extreme case to show that his theory will hold even then; and he clearly recognizes the fact that even comparatively small changes in the distribution of the iand would considerably affect the climate.

James Geikie, ' discussing Lyell's theory, says, "But we are assured that no euch distribution of land and water as Lyell thought necessary for the production of our Glacial Period ever obtained in Pleistocene times. We have no reason to doubt that the positions of land and sea were practically the same as they are now." But the view is now gaining ground that the changes in the distribution of land and sea which are known to have occurred in Pleistocene times were sufficient to affect the temperature appreciably.

Croll ${ }^{2}$ also dissented from Lyell's theory. He says," "The only other theory on the subject worthy of notice is that of Sir Charles Lyell. These extraordinary changes of climate are, according to his theory, attributed to differences in the distribution of land and water . . . It will be shown in subsequent chapters that this theory does not duly take into account the prodigious influence exerted on climate by means of the heat conveyed from equatorial to temperate and polar regions by means of ocean currents." Lyell did not go to the lengths Croll did on this subject; but that he was quite well aware of it and considered it the following remarks of Lyell show: "The general climate of Europe is materially affected by the volume of warmer water thus borne northwards; for it maintains an open sea free from ice in the meridian of East Greenland and Spitzbergen."

Mr. C. E. P. Brooks ${ }^{3}$ has recently devised an empirical method of calculating the probable alteration in the temperature that might be expected from known geographical changes in the outline of the continent of Europe during late geological times, and he considers that they were sufficiently great to cause the Glacial Period. Howerer, he recognizes that such changes could not account for the four great cold periods of the Pleistocene we are now coming to recognize. He suggests that the weight of the ice slowly weighed down the land until the new geographical conditions thus introduced caused the ice to disappear and the climate to ameliorate. On the

1 The Great Ice Age, 3rd ed., p. 792.

2 Climate and Time, p. 8.

${ }^{3}$ Quart. Journ. Roy. Met. Soc., vol. xliii, pp. 159-73, and vol. xliv, pp. 253-70. 
disappearance of the ice the land again slowly rose, reintroducing glacial conditions. This is supposed to have taken place four times in succession, each succeeding cold period being less severe than the last.

In Europe there may appear to be some evidence in favour of the view that the periods became less cold as they succeeded each other; but in America there is little evidence of this kind. In Europe during the first cold period the Straits of Dover probably did not exist and the ice advanced over the area now occupied by the North Sea. The opening of the straits at a later period much restricted the advance of subsequent ice-sheets.

I have suggested that the Glacial Period was the result of two agencies acting together. Separately they could not produce the required conditions; but jointly they could. It is well known that the great polar cyclones of the earth are acting in direct opposition to the gradient of temperature on the earth's surface, and produce the poleward flow of the air in temperate regions. ${ }^{1}$ The energy which keeps these cyclones in action is very probably cosmical and may undergo periodic fluctuations. In pre-Tertiary times the distribution of land was seldom such as to lower the temperature sufficiently to enable a temporary decrease in the strength of the polar cyclones to produce a glacial period. In Pleistocene times, however, the polar areas became so continental or landlocked that the periodic waning and strengthening of the polar cyclones led to alternating cold and warm periods.

Winds from the Poles towards the Equator do blow, of course, but they are not anticyclonic. They are merely surface winds, or winds resulting from travelling cyclones. The great cyclonic low-pressure areas of the Poles persist throughout the year.

\section{III.-On the Discover of a Quartzose Conglombrate at Caldon Low, Srafrs.}

By J. Wilfrid JACKSon, F.G.S., and W. E. Almins, B.Sc.

DUING a visit to the limestone quarries at Caldon Low last Jeptember we had the good fortune to discover an interesting exposure of a quartzose conglomerate containing numerous fossils. The bed was exposed in a strong joint-face running approximately N.N.W. to S.S.E., at the porthern extension of the quarry on the north-west flank of the Low, just beyond the mineral line of the North Staffordshice Railway. 'The altitude is about 900 feet $0 . D$. The conglomerate apparently extended some little distance to the south-west before the opening of the quarry, as we ascertained that some 20 or 30 yards had been removed in gaining access to the limestone behind. It appears to extend for some distance round the flank of the Low towards the north-east.

In the section exposed the conglomerate did not appear to possess definite bedding in its lower portion; but higher up the slope of the hill, on the S.S.E. side of the section, it was seen to pass upwards

${ }^{2}$ Phil. Mag., vol. xxx, pp. 13-33, July, 1915 ; vol. xxxi, p. 399, April, 1916 ; vol. xxxv, pp. 221-36, March, 1918. 